\title{
High-speed rail network development and winner and loser cities in megaregions: The case study of Yangtze River Delta, China
}

DOI:

10.1016/j.cities.2018.06.010

\section{Document Version}

Accepted author manuscript

Link to publication record in Manchester Research Explorer

Citation for published version (APA):

Wang, L., \& Duan, X. (2018). High-speed rail network development and winner and loser cities in megaregions:

The case study of Yangtze River Delta, China. Cities, 83, 71-82. https://doi.org/10.1016/j.cities.2018.06.010

\section{Published in:}

Cities

\section{Citing this paper}

Please note that where the full-text provided on Manchester Research Explorer is the Author Accepted Manuscript or Proof version this may differ from the final Published version. If citing, it is advised that you check and use the publisher's definitive version.

\section{General rights}

Copyright and moral rights for the publications made accessible in the Research Explorer are retained by the authors and/or other copyright owners and it is a condition of accessing publications that users recognise and abide by the legal requirements associated with these rights.

\section{Takedown policy}

If you believe that this document breaches copyright please refer to the University of Manchester's Takedown Procedures [http://man.ac.uk/04Y6Bo] or contact uml.scholarlycommunications@manchester.ac.uk providing relevant details, so we can investigate your claim.

\section{OPEN ACCESS}


High-speed rail network development and winner and loser cities in megaregions: The case study of Yangtze River Delta, China

\author{
Lei Wang ${ }^{\mathrm{a}, \mathrm{b}}$ and Xuejun Duan ${ }^{\mathrm{b}}$ \\ ${ }^{a}$ Manchester Urban Institute, School of Environment, Education and Development, The \\ University of Manchester, Manchester, UK \\ ${ }^{b}$ Key Laboratory of Watershed Geographic Sciences, Nanjing Institute of Geography and \\ Limnology, CAS, Nanjing, China
}

\begin{abstract}
Using a door-to-door approach to integrate inter- and intra-city travel times, this paper simulates the changes in regional territorial and population accessibility, spatial equity, as well as the winner and loser cities resulting from High-speed rail (HSR) network development in the Yangtze River Delta, China. HSR network development has a minimal effect on decreasing the disparity in overall territorial accessibility but leads to an obvious decrease in the disparity in population accessibility. Seven types of winner and loser cities are summarised according to their net winner population and stations locations. Poor access to the city centre from HSR stations is a common problem for many cities in the YRD, and more integrated development is needed for future HSR planning and construction.
\end{abstract}

\title{
Keywords
}

High-speed rail network; conventional rail network; inter-city travel time; regional accessibility; winner and loser cities; the Yangtze River Delta

\section{Introduction}

In the context of economic globalization, a substantial volume of literature and many policy documents have highlighted the important role of megaregions in economic organization and their strategic positions on a national scale (Harrison and Hoyler 2015, Li and $\mathrm{Wu}$ 2017, Scott and Storper 2007). The connections among cities in megaregions have been emphasised along with their polycentric tendencies (Liu, Derudder and Wu 2016). Several countries worldwide have set agendas to improve inter-city infrastructures in megaregions. For example, the UK government announced the strategy of the Northern Powerhouse to integrate Liverpool, Manchester, Leeds, Sheffield and Newcastle-upon-Tyne in northern England; it emphasised the development of inter-city infrastructure. To connect the major northern cities, a proposal for the construction of high-speed rail (HSR) 3 was supported by the UK government (Chen 2016). The US federal government recognised 11 megaregions in its America 2050 strategy and emphasised the establishment of new links in the mobility system. Among the new links, HSR is prioritised, and a plan was proposed for the Piedmont Atlantic Megaregion (Chandra and Vadali 2014). Similarly, China's central government proposed development plans for the megaregions of the Yangtze River Delta (YRD), Beijing-Tianjin-Hebei, and Pearl River Delta within which regional infrastructures, such as HSR development, account for a large percentage of government investment. 
Additionally, Poland, Russia, and Turkey are also planning HSR in their most developed regions.

HSR development in megaregions is popular worldwide for the following reasons. By shortening travel time and offering high-quality services, HSR is widely regarded as the most competitive transport mode at distances ranging from 200 to $800 \mathrm{~km}$ (Givoni 2006), which is a spatial scale that corresponds to megaregions. Additionally, it has advantages such as greater reliability and safety, lower energy consumption and carbon emission than other modes of transport (Levinson 2012, Cao and Zhu 2017). The development of HSR services can change the pattern of regional accessibility resulting in time and space compression and spatial restructuring (Ureña, Menerault and Garmendia 2009, Gutiérrez 2001, Chen and Vickerman 2017). However, what matters is whether inter-city accessibility improvements due to HSR network development change the uneven landscape of accessibility at the regional scale (Ureña et al. 2009). Monzón, Ortega and López (2013) evaluated the accessibility impacts on spatial equity of HSR network development and found a more polarised pattern in Spain. Case studies also showed that there was an enlarged accessibility disparity between central cities and periphery areas (Jiao et al. 2014, Givoni 2006). It is well known that HSR cities can benefit directly from reducing travel time to other HSR cities while the accessibility change in outlying cities is less understood (Jiao et al. 2014, Shaw et al. 2014, Wang et al. 2009). It is also worth to mention that the comparability of previous studies remains questionable as they have focused on different spatial scales and different types of measures and data sources.

Over the last decade, China has been keen on developing HSR networks for its vast territory, and high population density, as well as to tackle the capacity problem of CR (conventional rail) networks (Chen 2012, Wu, Nash and Wang 2014). The country has established the largest passenger-dedicated HSR network in the world, most of which is newly constructed. By the end of 2016, China had a network of 22,000 km HSR that was suitable for trains running at speeds of over $200 \mathrm{~km} / \mathrm{h}$; it accounted for more than $60 \%$ of the global length of HSR (UIC, 2016). In eastern megaregions, the HSR network has expanded so rapidly that it has almost caught up with the CR network for passenger transport (Ollivier et al. 2014). According to the most updated Mid-to-long Term Railway Development Plan (formulated in 2004 and further revised in 2008 and 2016), all cities with a population of over 500,000 will be connected by HSR that will have a total length of $38,000 \mathrm{~km}$ by 2025 . Rapid HSR network development has dramatically advanced inter-city accessibility. Perl and Goetz (2015) regarded HSR development in China as a distinct comprehensive model along with two other global models: exclusive corridor (e.g., Japan and the UK) and hybrid models (e.g., Germany and France). HSR development is assumed to have a complex impact on regional accessibility and spatial restructuring because of massive HSR network expansion and China's different development and station and line location strategy (Chen 2012, Chen et al. 2016b, Cao et al. 2013). Therefore, it is important to examine the changing pattern of regional accessibility in China at a megaregion scale, which would indicate some implications for other countries and regions that are interested in developing HSR.

By using a door-to-door approach that integrates the intra-city travel time to/from rail stations with inter-city rail travel time, this paper attempts to examine the changes in regional 
territorial and population accessibility at the multi-spatial scale of HSR development in one of the most developed megaregions in China - the Yangtze River Delta (YRD). The remainder of this paper is structured as follows. The second section provides a brief literature review of the state-of-art of HSR development and its spatial implications, followed by the introduction of methodology and data sources in the section three. The fourth section provides an analysis of the changing patterns of regional accessibility, the winner and loser cities, and the associated sub-types. Finally, a discussion and conclusion comprise the last section.

\section{Literature Review}

There have been hotly contested debates in in academic and policy circles on whether and how to develop HSR because of the high cost of infrastructure construction and service operation. A cost-benefit analysis is usually used to support decision-making on new transport projects (Hall and Banister 1993, Button 2012). Globally, only two lines were reported to be profitable: Lyon-Paris and Tokyo-Osaka HSRs (Ryder 2012). Particularly, concerns over financial instability caused by developing HSR projects have been raised in countries like the United States and the UK after the global financial crisis in 2008 (Banister and Givoni 2013, Button 2012). In consideration of the economic return, Button (2012) argued that HSR investment 'should be carefully targeted and tailored to circumstances' and particularly opposed the idea of nationwide HSR network development in the US and Spain. In contrast, Johnson (2012) supported HSR development to improve the poor state of passenger train service in the US and called for transit-oriented development around HSR stations. Similarly, to lower financial risk, Banister and Givoni (2013) also advocated integrating HSR investment with border economic development objects. Guirao (2013) reflected that a better integration of HSR and CR lines would have improved the profitability of HSR services in Spain. Massive HSR network development has resulted in the China Railway (the former Ministry of Railways) is heavily in debt. Thus, Wu et al. (2014) suggested that CR lines, much cheaper than HSR lines, are a better solution to China's less developed areas because the values of time remain low for most residents.

Generally, the purpose of developing HSR in many countries is to support broader economic projects (Guirao 2013, Vickerman 2017). For example, HSR in France was founded to support regional economic development policy (Ryder 2012). The HSR network was regarded as an important tool to promote regional integration in the EU (Mohino, Loukaitou-Sideris and Urena 2014). The UK High Speed 2 was justified to rebalance the long-standing north-south divide in England (Chen and Hall 2013). Even though the wider impacts are difficult to demonstrate, they are widely used to defend HSR projects all over the world. During the global financial crisis in 2008, the Chinese government announced a RMB 4 trillion Keynesian macroeconomic package to stimulate economic development. Much of the money went into developing HSR projects. HSR development in China is regarded as a state project and governed by the state-led planning mechanism (Wang, $\mathrm{Xu}$ and $\mathrm{He} 2013$ ). The top-down development approach may overlook the pattern of local inter-city transport demand. The locations of HSR stations reflected the power relations among the China Railway and hierarchical governments (Li et al. 2013). Big cities have strong bargaining 
power to locate HSR stations in line with their urban plans, while small cities have to comply with the directions from above (Zhu, Yu and Chen 2015).

Since the first HSR line was developed in Japan in 1964, HSR has been developed differently in many HSR counties to adapt with local context (Givoni 2006). Technically, there are two modes of HSR services: the maglev train and wheel-track train. Currently, there is only one commercial maglev HSR in the world, located in Shanghai to connect the Pudong International Airport and the city financial center with a length of $30 \mathrm{~km}$. Most HSR countries employed the mode of wheel-rail but with different approaches (Campos and de Rus 2009). The first type is to build the independent passenger dedicated line that is not compatible with CR lines. The prototype includes the Shinkansen in Japan and most newly built HSR lines in China. The second type is backward compatible with CR lines, such as TGV (Train à Grande Vitesse) system in France. That means HSR trains can be operated on CR tracks, but not vice versa. HSR in Spain and Germany also belongs to this mode, but only Germany's HSR trains share some tracks with freight trains (Vickerman 1997). The third mode is to upgrade CR lines to operate much cheaper HSR services at the speed of 200-250 km/h. Examples include HSR services in Sweden, Italy, and a few lines in China.

In HSR planning and development, Banister and Givoni (2013) argued that two issues are critically important and have significant impacts on regional accessibility: (1) the number and location of stations, and (2) the integration of HSR station with the rest of the transport network. Having been developed for decades, CR stations are usually incorporated in urban areas. Thus, HSR stations upgraded from CR stations are easy to access by most citizens. In contrast, the location of stations for newly built HSRs is much more complex because the construction cost in the urban areas is astonishingly high and HSR lines require relatively straight and flat trajectories (Wang et al. 2013). Therefore, some intermediate HSR stations were built in the suburban areas. Examples of such intermediate stations are widely distributed in Spain, Taiwan and Mainland China. However, most of the newly built HSR stations in Europe were built in the city center to better access the market and integrate with the urban transport network (Banister and Givoni 2013). Another consideration was to facilitate urban regeneration (Hall and Banister 1993). In contrast, the rationale of locating HSR stations in the suburban areas is more complicated in the Chinese case. China is still in the process of rapid urbanisation and peripherally located HSR stations are used as stimulators of new town development (Zhu et al. 2015, Wang et al. 2013). Subsequently, different strategies of HSR development result in different patterns of travel time saving, leading to a varied spatial restructuring and equity issues of accessibility improvement.

Various accessibility measurements have been developed to evaluate the impacts of the planning and construction of HSR projects. Gutiérrez (2001) examined the impacts of the Madrid-Barcelona-French border HSR in terms of three indicators: weighted average travel time, economic potential, and daily accessibility. Kim and Sultana (2015) formulated a systemised measurement to evaluate accessibility changes in the Seoul metropolitan area from HSR development in South Korea. Levinson (2012) predicted the potential accessibility impacts of HSR planning in the United States. Substantial literature and policy documents on accessibility calculation have emphasised the shorter inter-city rail travel time between stations from HSR development (Jiao et al. 2014, Kim and Sultana 2015, Chandra and Vadali 
2014). On the other hand, some highlighted the effects on intra-city travel time due to changes in the location of rail stations (Givoni and Banister 2012, Guirao 2013, Bellet 2016).

From the perspective of passengers, some studies are concerned more on the journey's total travel time than time spent using train services. Martínez and Givoni (2012) argued that accessibility assessment should not just focus on urban areas and stations; a wider geographic area must be considered in the multi-transport modes environment. Access to rail stations within a city varies spatially, and HSR stations must be integrated with an intra-city transport network that offers door-to-door service (Givoni and Banister 2012, Wang et al. 2013). Urban networks with different transfer modes must be incorporated as feeders to rail transport accessibility assessment (Ortega, López and Monzón 2012, Zhao and Li 2017). Rather than upgrading CR stations to be compatible with the HSR network, many cities in China have chosen to build brand new HSR stations in suburban areas, which increases the pressure on intra-city accessibility to HSR services (Diao, Zhu and Zhu 2016). Even within the rail system, the integration between HSR and CR networks should be considered in regional accessibility evaluation (Garmendia, Ribalaygua and Ureña 2012). Therefore, accessibility impacts of HSR development are characterised by multi-spatial scales within a system of multi-transport modes.

\section{Methodology}

\subsection{Study area}

Comparative perspectives across countries and time periods are important to the understanding of HSR development and its spatial implications (Givoni 2006, Garmendia et al. 2012, Campa, López-Lambas and Guirao 2016). In China, rail network plays an important role in transport supply. It accounted for 39.8\% of land-based passenger traffic in 2015. Comparing to other rail countries with a top stock of railways in the world, China had relatively lower railway density (Figure 1). The figure was less than one-tenth of that in the UK, France and Germany. However, the rail network for passenger transport was used most heavily in China (Wu et al. 2014). Figure 1 shows that China's rail passenger density ranked the second among nine major rail countries in the world. Highest rail passenger density suggests that rail development in China might lag behind economic growth.

Indeed, China has witnessed massive growth in traffic volumes over the past decades of rapid economic development. Government at various levels were keen to develop transport infrastructures to satisfy the increase in mobility demand and sustain economic growth. Figure 2 shows that rail passenger volume in 2015 was $263.8 \%$ more than that in 2000 . The volume stabilised at the beginning of the 2000 s due to the overcapacity of the rail network. However, it began to grow after the speed-up campaign of China's rail services in 2004. It has been growing even faster since the introduction of the HSR services in 2007. Generally, the share of rail transport in the land-based traffic tended to decrease since 2000. This is because economic affluence makes private cars affordable for many Chinese families. However, the share of rail services was still very high, compared to the figures of less than $10 \%$ in many European countries reported by Banister and Givoni (2013). Due to the change of the statistical method to measure road traffic in China, the share of rail services recorded a big jump in 2012/2013. However, the figure increased from $38.4 \%$ in 2013 to $39.8 \%$ in 2015; this 
suggests that rapid HSR development reversed the declining trend of the share of rail services.

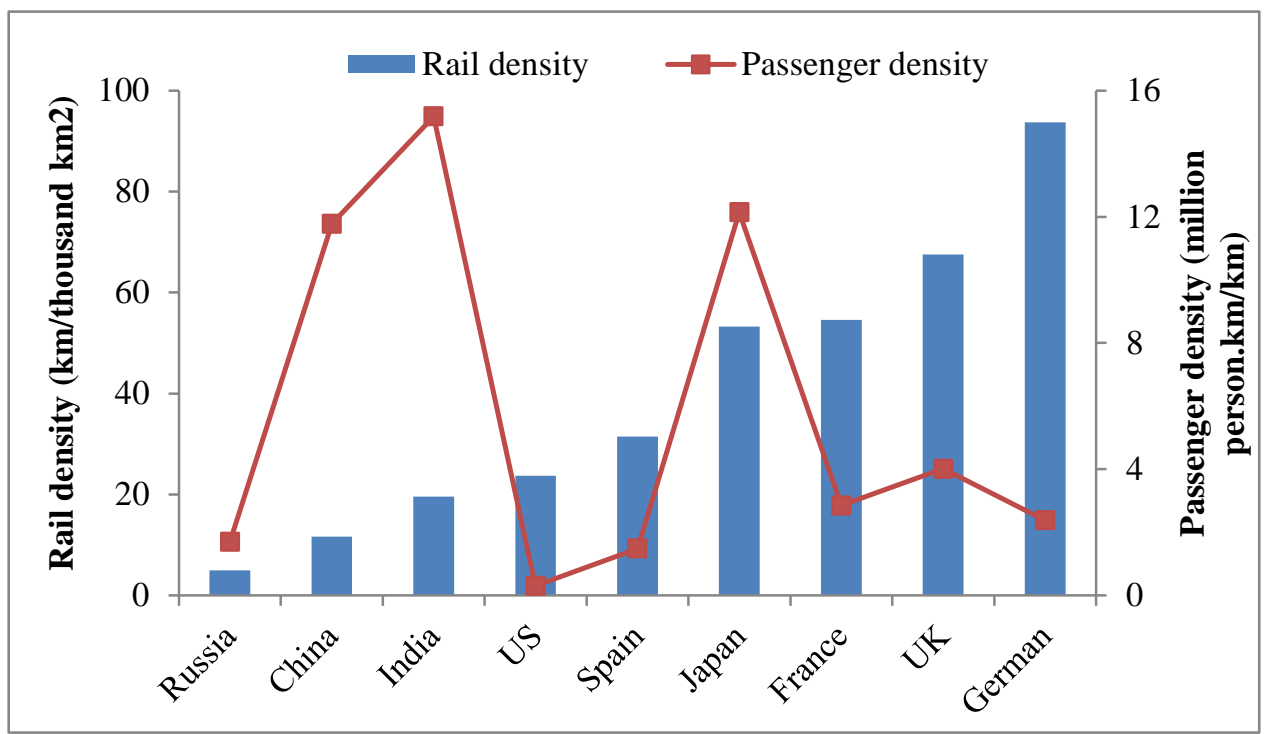

Figure 1 Rail density and passenger density in some rail countries, 2013

(Data source: China Railway Statistics Yearbook 2014)

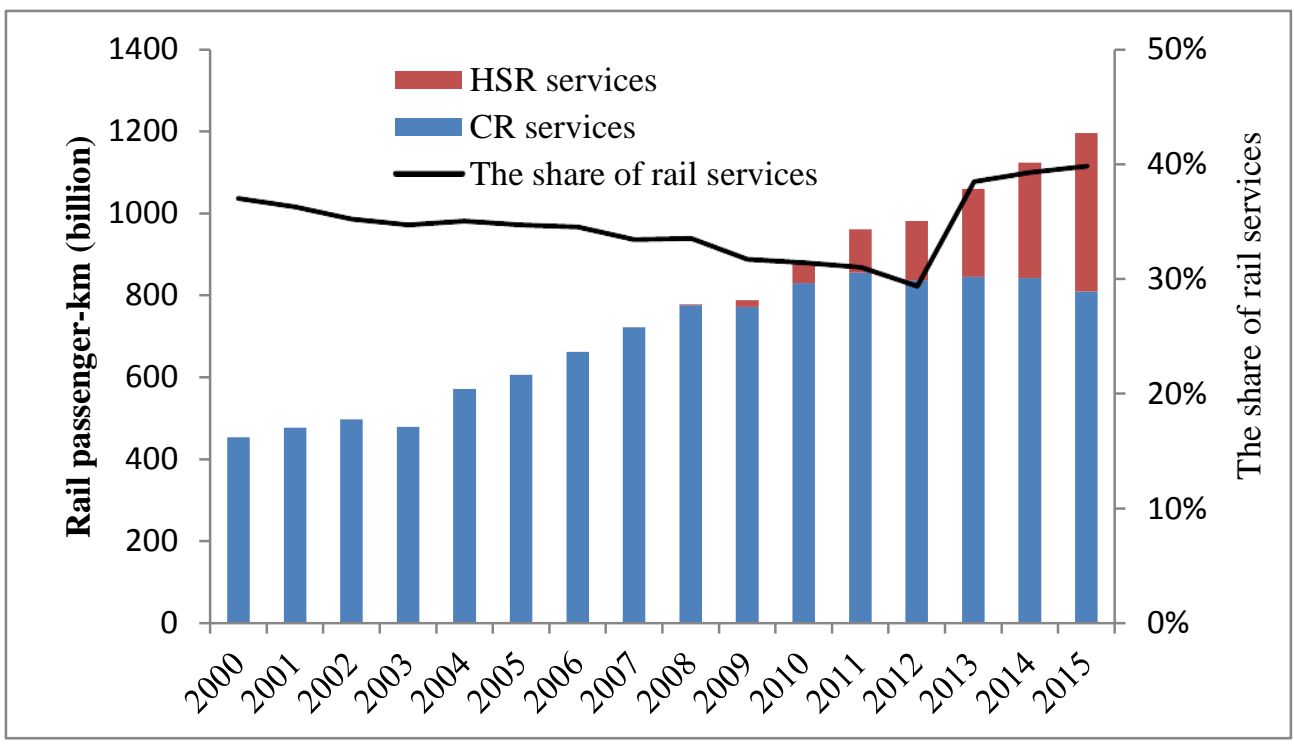

Figure 2 The growth of rail passengers and the share of rail services in the land-based traffic in China, 2000-2015

(Data source: China Statistical Yearbook, 2001-2016)

Located in the eastern coastal areas of China (Figure 3), the YRD has long been a policy focus of China's central government. In 2015, the YRD accommodated a population of 220.7 million, and had a GDP of US16,013.2 billion. After several rounds of regional planning, the YRD territory has expanded from 15-member prefectures in three provinces in the late 1990s to 25 prefectures in four provinces in the last regional plan of 2016. Considering the continuous expansion of the YRD and China's railway administrative system, the territorial focus of this paper is the so-called 'expanded YRD' which encompasses the four province units of Shanghai, Jiangsu, Zhejiang, and Anhui and 42 prefectures. The railway system in 
this region is administrated by the Shanghai Railway Bureau, one of the largest among the 18 local branches of China Railway. Both CR and HSR are well developed in the YRD. By April 2017, the length of the CR passenger network was approximately 7,000 km and the length of the HSR network was over 3,000 km. There are 192 passenger railway stations covering 122 county-level units, of which 122 stations can operate HSR services within 99 county-level units. Therefore, the YRD is a typical case for the study of changes in regional accessibility as a result of HSR network development.

Multi-scalar spatial analysis is used to conduct regional accessibility assessment. The basic spatial unit used to map the accessibility surface of the YRD is the $100 \mathrm{~m} \times 100 \mathrm{~m}$ grid. We obtain the accessibility surface by calculating the travel times from all the grids of the YRD (34.81 million). Another spatial analytical unit is the county-level or above administrative units. These are used to aggregate relative gains and loss at the grid level into administration units of the HSR network. In China's railway system, the county-level unit is the lowest administrative level for rail station construction. The higher the level of administration ${ }^{1}$, the higher the level of railway stations built and more the number of trains stopping (exceptions are some lower level administration units located at rail network junctions such as Yiwu and Kunshan). Additionally, regional and sub-regional level analysis is performed to evaluate the spatial variations of accessibility in the YRD.

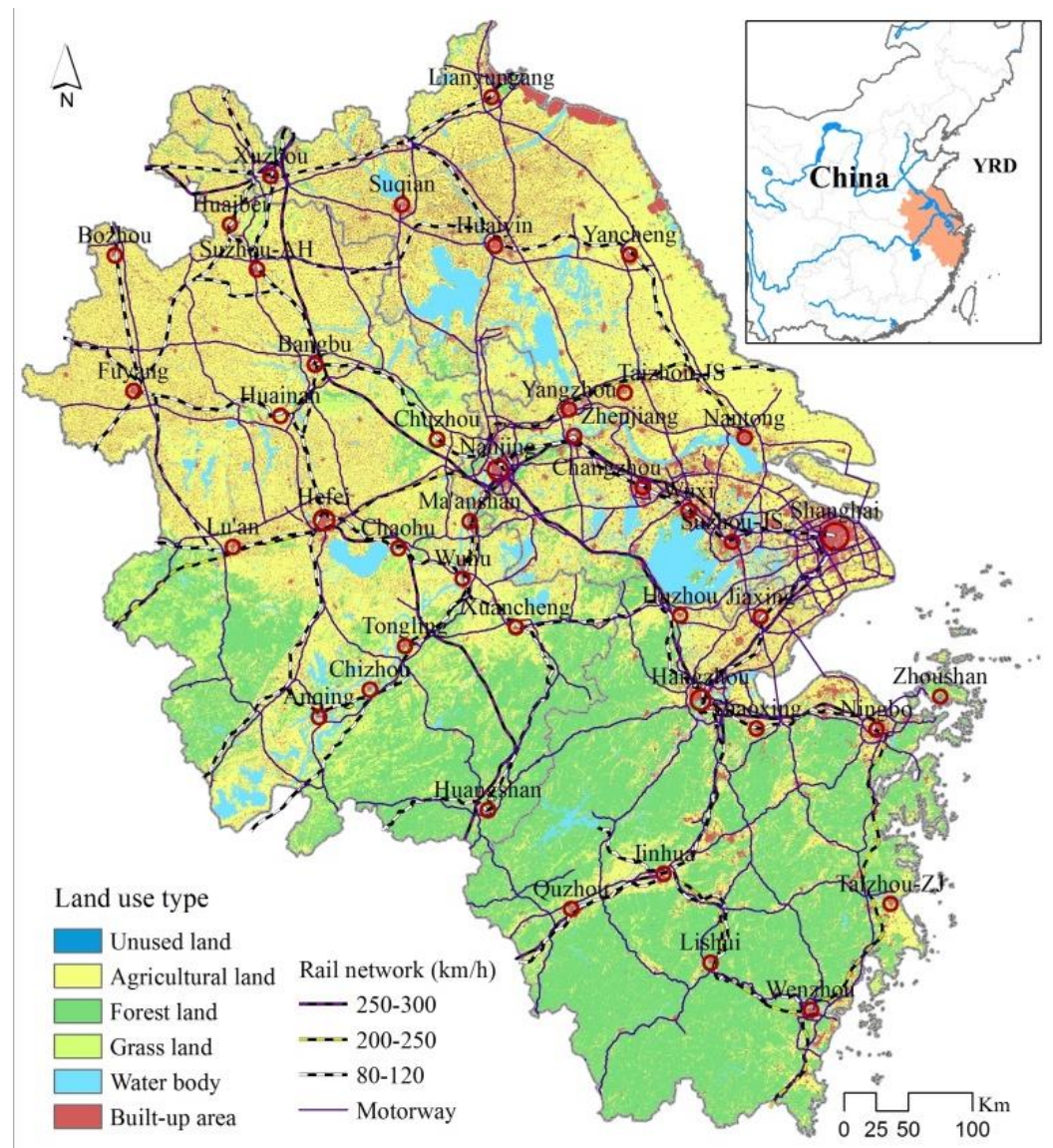

\footnotetext{
${ }^{1}$ Cities in China are designated at different administrative levels, that is, from top to bottom there are provincial level cities (Shanghai), vice-provincial level cities (Nanjing, Hangzhou, and Hefei), prefecture level cities (Suzhou, Jiaxing, Wuhu, etc.), county-level cities (Kunshan, Changxing), and rural counties (Hexian, Jianhu).
} 


\subsection{Research process}

Figure 4 outlines the methodological steps of the study. We explore the winner and loser cities in the YRD using a bottom-up approach by considering individuals' relative accessibility gains or losses. Previous studies typically considered population as an endogenous factor of accessibility and employed it as a weight variable in the accessibility index and then compared accessibility values before and after HSR operation to identify loser and winner cities (Jiao et al. 2014, Gutiérrez 2001). However, in this paper, we highlight the resident losers and winners in HSR development. A city's performance depends on the aggregated situations of its residents, who are unequally distributed spatially. The winner and loser residents are recognised by their travel time saving, which might be higher or lower than the average improvement of HSR development in the YRD. The travel time saving is calculated by comparing two scenarios of HSR-led regional accessibility and CR-led regional accessibility. The CR-led regional accessibility patterns are obtained by assuming the absence of HSR service, while HSR-led regional accessibility patterns are calculated on the basis of the actual operation of both HSR and CR services in the YRD.

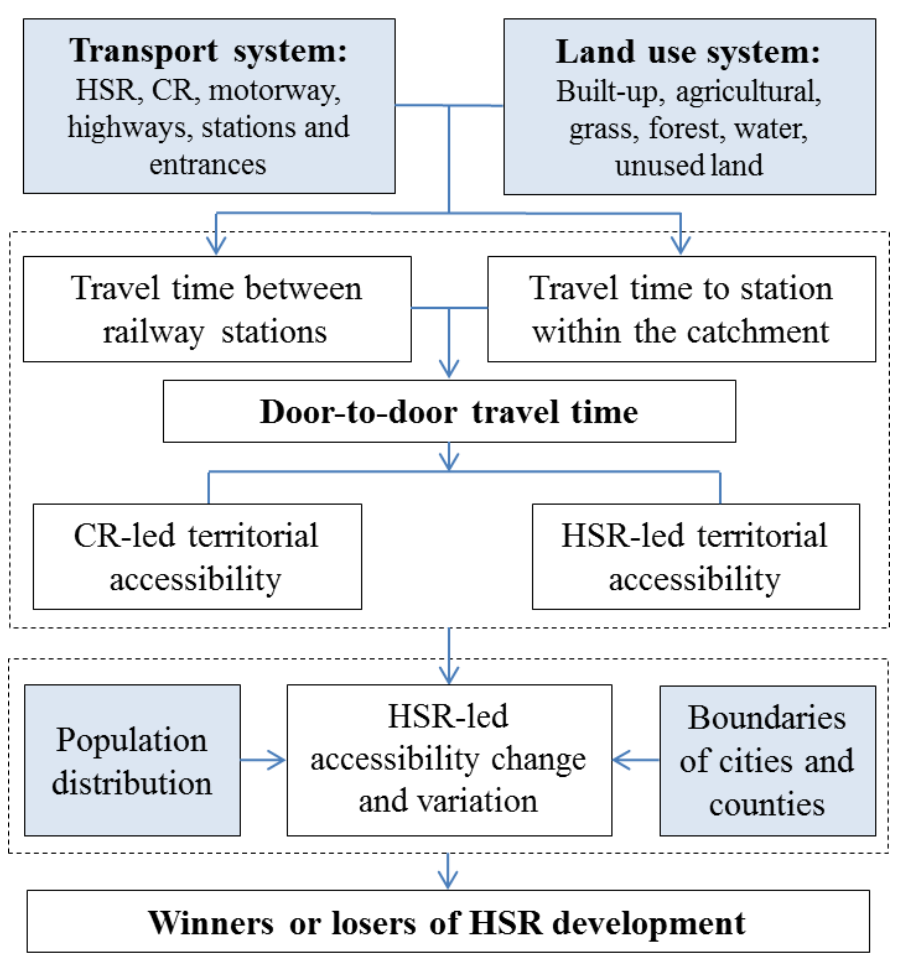

Figure 4 Outline of the methodological steps

\subsection{Key accessibility measures and data sources}

Based on previous studies (Wang et al. 2016, Wang et al. 2013, Salonen and Toivonen 2013), we employ a door-to-door approach to calculate the total inter-city travel time if rail services are chosen. Figure 5 shows that the total travel time from an origin in city (a) to a destination in city (b) includes three parts: (1) intra-city travel time to station before departure $\left(\mathrm{T}_{1}\right)$; (2) inter-city travel between two stations $\left(\mathrm{T}_{2}\right)$; and (3) intra-city travel after arrival from the rail station to the destination $\left(\mathrm{T}_{3}\right)$. The total travel time is thus defined as: 


$$
\mathrm{T}_{A \rightarrow B}=\mathrm{T}_{1}+\mathrm{T}_{2}+\mathrm{T}_{3}
$$

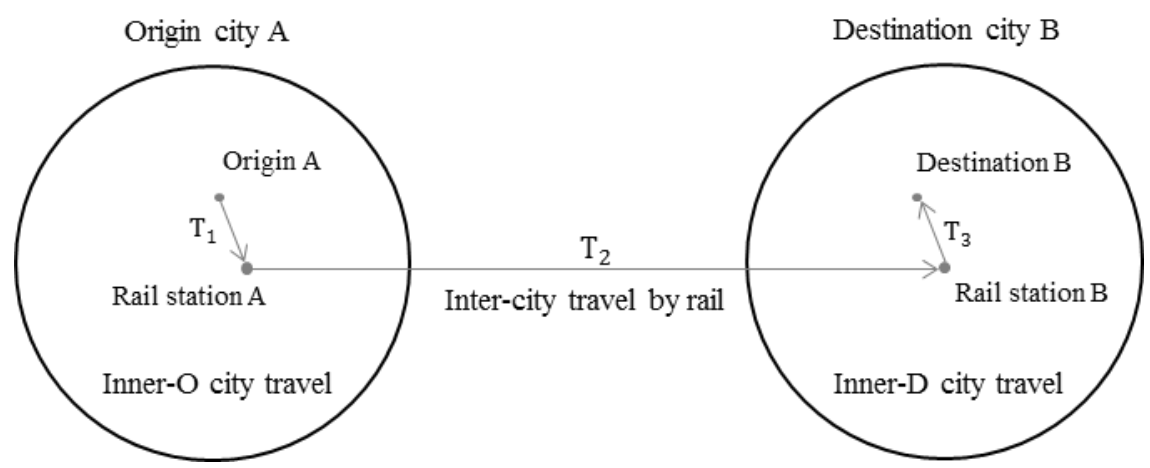

Figure 5 Conceptualising the inter-city travel time through a door-to-door approach

For modelling a journey's travel time in a Geographic Information System (GIS) environment (Monzón et al. 2013), the cost distance analysis and network analysis are the two major methods, and they are operated with vector dataset and raster dataset respectively. By integrating the two methods, a hybrid approach is used to calculate regional accessibility to overcome the crossover problem in the road network for cost distance analysis and the low spatial resolution for network analysis. Specifically, the intra-departure city travel time $\left(\mathrm{T}_{1}\right)$ and intra-arrival city travel time $\left(\mathrm{T}_{3}\right)$ are calculated by cost distance analysis of the urban road system, whereas the inter-city rail travel time is calculated with network analysis of the rail network.

For the cost distance analysis of intra-city travel time, we establish the following calculation rules and processes: (1) building layers of travel cost raster on different land-use types, transport networks, and infrastructures and calculate the minimum travel cost of all grids for all possible travel modes; (2) given that it is a semi-closed system, a two-sided buffer of barriers along the rails and motorways with low travel speeds is defined to ensure that the journey starts from rail stations and motorway entrances, respectively. A transfer time of 30 minutes is used and buffered around rail stations when a journey involves a transfer to rail services from road networks and a transfer time of 5 minutes for motorway entrances when a journey transfers from ordinary roads; and (3) each grid is allocated to a station catchment that is zoned by minimum travel cost; this resembles the reality as people tend to choose a rail service that is closer to their residences. Due to data limitations, many studies typically employ the administrative boundary as station catchment but this tends to be less meaningful in functional terms.

For the network analysis of inter-city travel time between stations, the travel speeds of different train services in the YRD are used. There are two types of HSR train in China. One operates on the upgraded CR and lower-standard HSR that has a travel speed of $200-250$ $\mathrm{km} / \mathrm{h}$; the other is a more advanced system with a travel speed of $300-350 \mathrm{~km} / \mathrm{h}$. The speed of CR trains varies from 80 to $120 \mathrm{~km} / \mathrm{h}$ depending on the number stops the train makes. In this paper, we use the average travel speed of different types of train services to model inter-city rail travel time (Table 1). The speeds of other transport modes and on different land-use types are also regulated according to local design specification for road infrastructures and previous literature. Additionally, a one-time transfer of 30 mins is added if 
there is no direct train service between any two cities, and the information can be obtained from official train timetables. Similarly, the principle of minimum travel time is used in the network analysis.

Rather than using a composite accessibility index, we separate accessibility into two categories: territorial accessibility and population accessibility. We measure regional territorial accessibility by taking the total travel time, as travel time is considered an intuitive measure corresponding to people's perception of distance (Salonen and Toivonen 2013). As in many studies (Monzón et al. 2013, Wang et al. 2013), we also choose a group of major cities to represent the destination. There are 42 cities at the prefecture level and above ${ }^{2}$ that are spatially distributed in the YRD. Finally, we define the physical distance to a city as the road and rail distance to its city centre. Thus, regional territorial accessibility of a grid $i$ is defined as follows.

$$
\mathrm{RT}_{i}=\sum_{j=1}^{42} T_{i \rightarrow j}
$$

The purpose of transportation is to satisfy a demand for mobility, as transportation can only exist if people have to travel (Rodrigue, Comtois and Slack 2016). We further develop the index of population accessibility to reflect the transport demand of a place. It is calculated by weighting the population variable to territorial accessibility. We also examine the change in spatial equity of territorial accessibility and population accessibility. The coefficient of variation $(\mathrm{CV})$ is calculated and compared to show the change in accessibility inequity from CR network to HSR network. The following is the formulation for calculating the CV of regional population accessibility:

$$
\mathrm{CV}=\sigma^{\mathrm{RT}} / \frac{\sum \mathrm{RT}_{\mathrm{i}} \mathrm{P}_{\mathrm{i}}}{\Sigma \mathrm{P}_{\mathrm{i}}}
$$

where $\sigma^{\mathrm{RT}}$ is the standard deviation of accessibility value grid $\mathrm{RT}_{\mathrm{i}}$ weighted by its population $P_{i}$ in the YRD.

The geographic datasets of the transport network and facilities, land use, and population are from different sources. The transport data, that is, types of road, railway, stations, and motorway entrances mainly come from the 2016 electronic atlas of the local and national transport department in 2016, but we updated the rail system data, as of April 2017, to reflect the most recent HSR development in the YRD. The administration boundaries and city centres are collected from national administration maps. Access most recent high-resolution data on land-use and population are rather difficult. Only datasets in 2010 are available for both categories. The datasets for land-use and population distribution come from the Global Land Cover Datasets (GlobeLand30) and WorldPop spatiotemporal change dataset, respectively. The two datasets have been widely used in previous academic research (Liu, Derudder and Wang 2017, Gaughan et al. 2016) and we resampled these datasets to $100 \mathrm{~m}$ in line with our basic analytical unit.

\footnotetext{
2 Administration at the level of prefecture or above in China indicates a city-region because a group of small cities is administered by a central city. The central city is usually the political and economic centre of the administration.
} 
Table 1 Modelling travel speeds of different transport modes and land-use types

\begin{tabular}{ll|lc}
\hline Transport modes & Speeds $(\mathrm{km} / \mathrm{h})$ & Land-use types & Speeds $(\mathrm{km} / \mathrm{h})$ \\
\hline HSR train I & 300 & Built-up area & 20 \\
HSR train II & 250 & Agricultural land & 15 \\
CR train & 120 & Grassland & 10 \\
Motorway & 110 & Forest land & 2 \\
National highway & 80 & Waterbody & 5 \\
Provincial highway & 70 & Unused land & 5 \\
City and county highway & 40 & & \\
Streets & 30 & & \\
Rail buffer of barrier & 0.15 & & \\
Motorway buffer barrier & 0.1 & & \\
\hline
\end{tabular}

\section{Modelling changes in regional accessibility in the YRD from HSR development}

\subsection{Territorial accessibility patterns for the CR and HSR networks}

Figure 6 shows the patterns for regional territorial accessibility by the CR and HSR networks and the percentage of change between the two scenarios. To highlight the travel time compression from the HSR network, we use the nature break grouping scheme to divide the territorial accessibility for the HSR network and to provide a benchmark to group the pattern for the CR network.

For the CR network (Figure 6a), the highest territorial accessibility (124 to $163 \mathrm{~h}$ ) is mainly clustered in the geographic centre of the region (e.g., cities of Nanjing, Zhenjiang, and Ma'anshan). The areas in various corridors radiating from the geographic centre are highlighted, as in the case of Changzhou, Wuxi, and Huzhou in the east and Bangbu, Huainan, Hefei, and Tongling in the west. The highest value zone only accounts for $7.9 \%$ of the territory in the YRD, while the lowest territorial accessibility ( 299 to $403 \mathrm{~h}$ ) emerges in the periphery areas (northern Jiangsu, northern Anhui, southern Zhejiang) and also in areas with poor CR services (coastal Zhejiang and coastal Jiangsu). The lowest accessibility values account for $9.5 \%$ of the YRD territory.

In contrast, territorial accessibility improved significantly with the extension of the HSR network (Figure 6b). The accessibility level increased throughout the territory, and the average improvement was $23.4 \%$. However, it is significantly lower than the average percentage change in travel time saving of the rail network (51.2\%). The highest territorial accessibility ( 88 to $133 \mathrm{~h}$ ) increased by one-third and expanded dramatically to account for $18.4 \%$ of YRD territory. Higher territorial accessibility values are mainly located in the areas around HSR stations. Additionally, some enclaves with higher values also emerge in the periphery areas, such as, Xuzhou, Liu'an, Huangshan, Quzhou, and Jinhua. The pattern shows that the HSR network helps the geographically peripheral cities (e.g., Xuzhou, Ningbo, and Shanghai) to overcome their barriers to territorial accessibility. Correspondingly, the lowest regional accessibility (with only $1.3 \%$ of the territory) shrinks drastically and is mainly located in the economically backward areas, mountain areas, and water bodies with few inhabitants, such as the northern Jiangsu province and the southwestern Zhejiang province. 
Figure 7 shows the two parts of territorial accessibility for the 41 rail cities at the prefecture level or above in the YRD. The location of cities in the region and the location of 3 HSR stations in the city has significant impact on regional accessibility in terms of the inter-city rail travel time and intra-city travel time, respectively. However, the HSR network 5 and good intra-city transport network can reduce the locational disadvantages. Obviously, the average inter-city rail travel time for HSR cities (108.95h) is much shorter than that for CR cities (147.52h). In contrast, intra-city travel time for HSR cities (34.73h) is longer than that for CR cities (33.81h). Among the 41 major cities, the geographically central HSR cities, such as Wuhu, Ma'anshan, Changzhou and Nanjing enjoy relatively shorter inter-city rail travel times, while peripheral CR cities experience the longest relevant travel times. In terms of the intra-city travel time, Tongling $(23.72 \mathrm{~h}$ ) has the lowest value, which is about one-third of that for Huangshan (67.16h), the city with the highest value. The ratio of intra-city travel time to inter-city rail travel time is relatively higher for those HSR cities having a central location in the YRD. The result suggests that the decrease in inter-city rail travel time makes intra-city travel a more sensible option for HSR users.
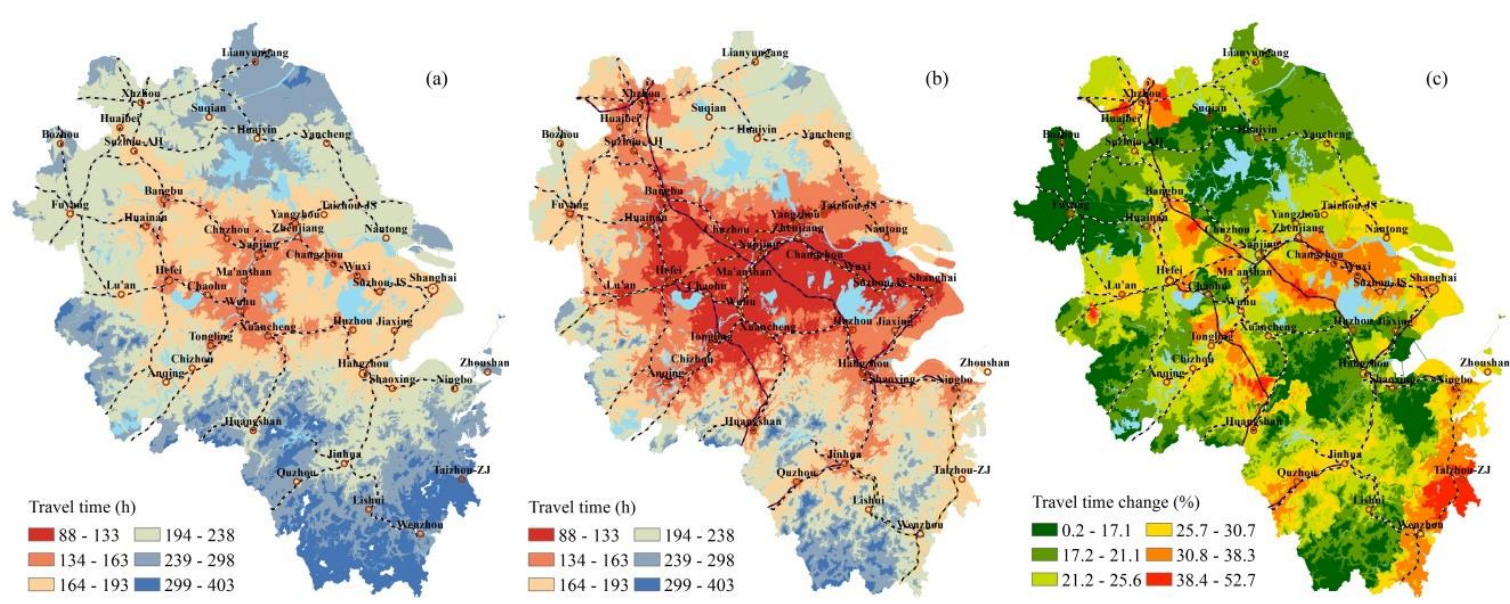

Figure 6 Territorial accessibility patterns and the percentage change from the CR to HSR network in the YRD

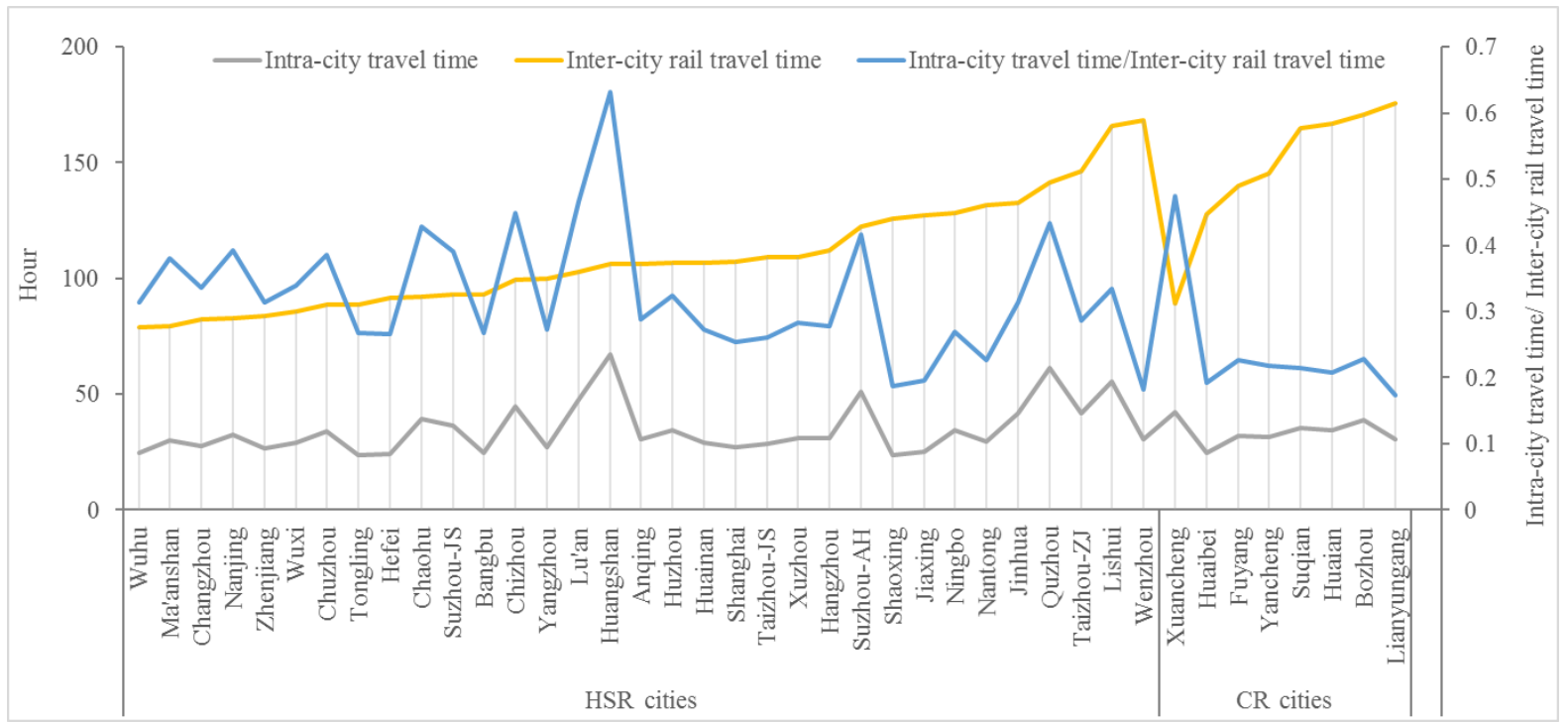

Figure 7 Two parts of regional territorial accessibility for major cities in the YRD 


\subsection{Changes in regional accessibility from the CR to HSR network}

Territorial accessibility change from the HSR network varies across the region, the stations, and their surrounding areas. As shown in Figure $6 \mathrm{c}$, the areas with the greatest improvement (38.4 to 52.7\%) are scattered across the region and are found in two types of areas. The first type is mainly found in areas where there were no rail stations before the HSR services, for example, cities along the Ningbo-Taizhou HSR and the Nanjing-Hangzhou HSR. The example of Taizhou city in Zhejiang province shows that the new HSR line reversed its poor situation in territorial accessibility in the region. The second type of area is HSR cities located in the peripheral areas where CR service alone could not overcome the location disadvantage and Xuzhou and Quzhou are examples.

However, over $70 \%$ of the territory's regional territorial accessibility change value is below $30 \%$. It is interesting to find that some HSR cities belong to the group with the lowest territorial accessibility change such as Caohu, Suzhou-AH, and Jiaxing. These HSR cities show a change of less than $20 \%$ due to the poor connections from HSR stations, which means that the cities benefit less than they were supposed to from the introduction of the HSR network. Suzhou-AH in Anhui province, for example, the city's HSR station is $31 \mathrm{~km}$ away from the city centre. The HSR station was built on farmland and poorly connected with nearby cities and towns, which prevents it from reaping the benefits associated with inter-city travel via HSR service. The journey by car from the city centre takes less than 5 minutes to reach the CR station, but 42 minutes to reach the HSR station. Moreover, only two public buses operate every 10 minutes and take 100 minutes to travel between the HSR station and the city centre. Similarly, for Jiangxing city in Zhejiang province, the journey from the city centre takes only 10 and 30 minutes to the CR station by car and by bus respectively, while the figures increase to 20 and 60 mins for travel to the HSR station. The result suggests that intra-city transportation to the HSR station is critical when considering territorial accessibility improvement of the region.

We also examine changes in spatial equity of territorial and population accessibility of the transition from the CR network to the HSR network of the YRD. The CV for territorial accessibility of the HSR network (0.22) is slightly higher than that of the CR network $(0.21)$. The small difference shows that HSR network development has not altered the overall spatial unevenness of regional territorial accessibility. However, there are significant local variations. The CV value for territorial accessibility change $(0.28)$ is much higher, which suggests some places obtain more gains than others. Population accessibility exhibits a more unbalanced distribution pattern in the YRD. However, the HSR network decreases the uneven pattern of population accessibility of the CR network by $8.1 \%$, from the CV value of 1.69 to 1.55 . Although geographically concentrated in certain corridors, the HSR network, combined with the CR network, decreases the unequal pattern of rail services for the YRD population. The situation in Europe is different, as HSR was mainly built between the most populous cities (Vickerman 1997, Diao et al. 2016). In contrast, the HSR development strategy in China not merely replaces the busiest CR lines, but also attempts to increase the country's rail service coverage (Shaw et al. 2014). In general, rail density in China is still lower than most developed countries (Wang et al. 2012), even in the YRD, which is one of the most developed regions in China. For example, sub-regions in north Jiangsu and southwest coastal Zhejiang 
have only had rail service in the past decade. Some HSR lines were built on "vacant land"

2 that never had rail development before.

3 Table 2 The disparity in regional accessibility and the change from a CR network to an HSR 4 network in the YRD

\begin{tabular}{lcccccc}
\hline & \multicolumn{3}{c}{ Territorial accessibility } & \multicolumn{3}{c}{ Population accessibility } \\
\cline { 2 - 7 } & Average $(\mathrm{h})$ & SD & CV & Average $(\mathrm{h})$ & SD & CV \\
\hline CR-led travel time & 214.70 & 44.60 & 0.21 & 982.52 & 1660.81 & 1.69 \\
HSR-led travel time & 164.20 & 36.00 & 0.22 & 749.33 & 1163.61 & 1.55 \\
Change & $23.40(\%)$ & 6.60 & 0.28 & $23.40(\%)$ & 6.60 & 0.28 \\
\hline
\end{tabular}

\section{$5 \quad 4.3$ Types of winners and losers cities of HSR development}

We explore the winner and loser cities by aggregating their respective populations at the grid level. There are four steps: (1) locating the winner and loser grids based on their regional territorial accessibility change above and below the average improvement percentage $(23.4 \%)$; (2) weighting the winner and loser grids by their population to acquire winner and loser populations at the grid level; (3) aggregating net winner populations through city boundaries; (4) defining winner cities with a threshold of net winner population up to half of the total population. Figure 8 shows the distribution of winner and loser cities in the YRD resulting from HSR network development. The winner cities from HSR network development are mainly located in places that have developed HSR and CR networks (e.g., the mid-YRD) and in the geographically peripheral areas with HSR stations (e.g., coastal Zhejiang and north-western Jiangsu). In contrast, most losers are those cities with no HSR service within their jurisdictions and in their vicinity. However, there are some unusual HSR cities that are losers such as Hangzhou and Suzhou-AH. The result also echoes a case study in Hangzhou (Diao et al. 2016) where the inter-city rail travel time improvement was crippled by the prolonged intra-city travel time to the HSR station. 


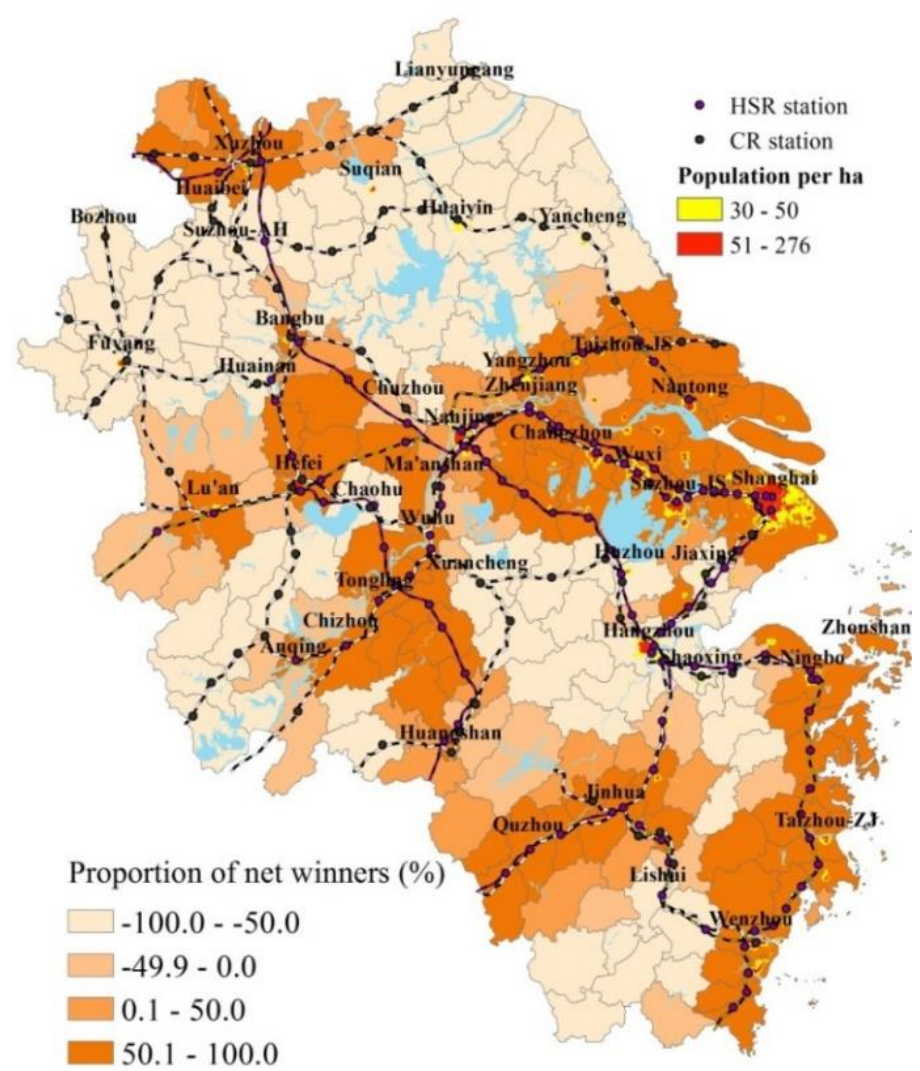

Figure 8 The winner and loser cities of HSR network development in the YRD

Our evaluation shows that the existence of an HSR station is not the only factor determining whether a city benefits from HSR network development. The location of the HSR station and its accessibility to most people within the city are also important. The YRD exhibits seven types of winner and loser cities with different spatial patterns for territorial accessibility improvement, HSR station location, and population distribution (Table 3).

Winners of type I are mainly the megacities, such as Shanghai, with several rail stations that can be easily accessed by most of the city's population; further some CR stations close to the city centre were upgraded to HSR stations. Winners of type II are cities such as Anqing in Anhui province where the CR stations were upgraded to HSR stations. Most cities in the upgraded Nanjing-Nantong Line, and the cities of Quzhou and Jinhua with upgraded CR stations for the new HSR line belong to this type. Winners of type III are represented by Taizhou-ZJ, which had no rail services before the introduction of HSR. HSR stations are typically built in suburban areas to save construction costs, but this significantly diminishes the city's rail accessibility. Winners of type IV are small cities such as Taicang, Changshu, Jingjiang, and Pinghu, which benefit from the spill-over effect of neighbouring HSR services. This implies that it is not necessary for some small cities to build costly HSR stations and it is often more efficient to build a relatively cheap motorway to improve its accessibility by connecting to the nearby HSR stations.

Turning to the losers, an example of type I losers is Shaoxing in Zhejiang province, which is an HSR city. The result shows that an HSR station does not secure better regional accessibility improvements if the station is located far from the city centre and is less accessible for most people. Losers of type II and III are marginalised by the development of 
1 an HSR network because of their remote locations and backward economies. The relative 2 distance of an HSR station from a CR station plays an important role in deciding whether an 3 HSR city is a winner or a loser. This is because CR stations have shaped urban development 4 for decades in the YRD, and the surrounding areas either became the city centre or attracted a 5 large population. Therefore, most CR stations in the YRD are accessible from the city. In 6 contrast, many newly built HSR stations are in suburban areas and are less accessible (Figure 7 9). Additionally, with only a decade of development, the stations' surrounding areas are far 8 less developed in some mid-sized and small HSR cities.

9 Table 3 Different types of winner and loser cities from HSR network development in the YRD

\begin{tabular}{|c|c|c|c|c|}
\hline \multicolumn{2}{|c|}{ Types } & Main features & Major cities & $\begin{array}{l}\text { Example city } \\
\text { from Figure } 8\end{array}$ \\
\hline \multirow{4}{*}{ Winners } & I & $\begin{array}{l}\text { Rail hubs with several CR } \\
\text { and HSR stations covering } \\
\text { most of the population }\end{array}$ & $\begin{array}{l}\text { Shanghai, Ningbo, } \\
\text { Hefei, Xuzhou, } \\
\text { Nanjing }\end{array}$ & \\
\hline & II & $\begin{array}{l}\text { HSR station upgraded } \\
\text { from CR stations and close } \\
\text { to the city centre }\end{array}$ & $\begin{array}{l}\text { Wuhu, Quzhou, } \\
\text { Jiangshan, Longyou, } \\
\text { Jinhua, Yiwu, Zhujia }\end{array}$ & \\
\hline & III & $\begin{array}{l}\text { No rail service before HSR } \\
\text { and HSR station is far } \\
\text { from city centre }\end{array}$ & $\begin{array}{l}\text { Taizhou-ZJ, Liyang, } \\
\text { Yixing, Dingyuan, } \\
\text { Fenghua, Ninghai, } \\
\text { Cangnan }\end{array}$ & \\
\hline & IV & $\begin{array}{l}\text { No HSR station but with } \\
\text { good accessibility to a } \\
\text { neighbouring HSR station }\end{array}$ & $\begin{array}{l}\text { Taicang, Changshu, } \\
\text { Jingjiang, Pinghu, } \\
\text { Changfeng, Huoqiu } \\
\text { Solid town, Fengxian }\end{array}$ & \\
\hline \multirow{3}{*}{ Losers } & I & $\begin{array}{l}\text { Has HSR station but far } \\
\text { from city centre }\end{array}$ & $\begin{array}{l}\text { Shaoxing, Hangzhou, } \\
\text { Suzhou, Huainan, } \\
\text { Lishui, Chuzhou } \\
\text { Jiaxing, Huzhou, } \\
\text { Suzhou, Shangyu, } \\
\text { Changxing, Deqing }\end{array}$ & \\
\hline & II & $\begin{array}{l}\text { Only has CR station but } \\
\text { poor accessibility to the } \\
\text { nearest HSR station }\end{array}$ & $\begin{array}{l}\text { Lianyungang, } \\
\text { Suqian, Yancheng, } \\
\text { Fuyang, Xuancheng }\end{array}$ & \\
\hline & III & $\begin{array}{l}\text { No railway station and } \\
\text { poor accessibility to the } \\
\text { nearest HSR station }\end{array}$ & $\begin{array}{l}\text { Anji, Lin'an, } \\
\text { Longquan, Guangde, } \\
\text { Sheyang, Guannan, } \\
\text { Xuyi, Jinhu, Gaoyou, } \\
\text { Yuexi }\end{array}$ & \\
\hline
\end{tabular}




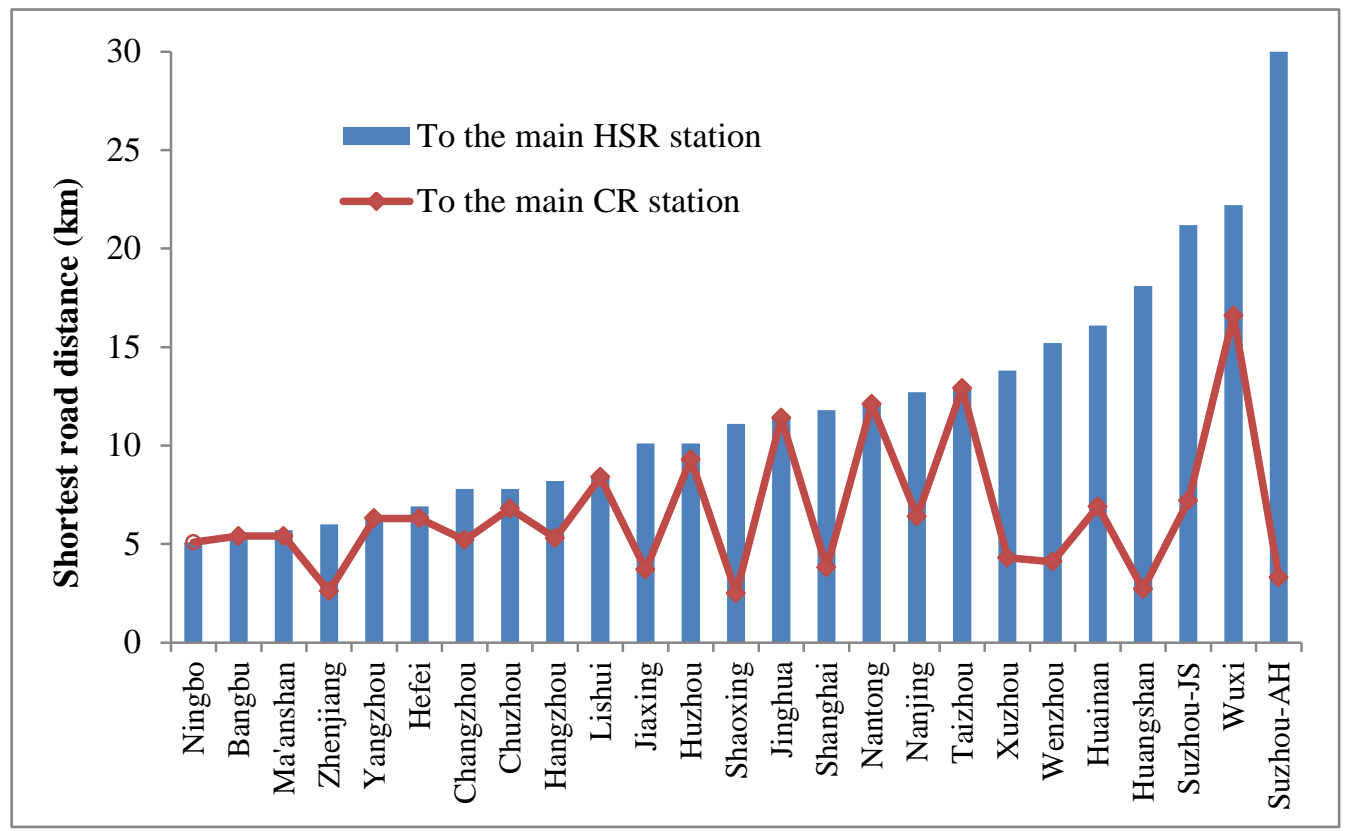

Figure 9 The shortest road distances from the city centre to the main CR station and the main HSR station for major HSR and CR cities in the YRD (data source: Baidu map)

\section{Discussion and conclusion}

Compared to the era without HSR service, HSR networks have significantly improved regional accessibility and connectivity. However, what is contentious is whether the major infrastructural network investment has created an uneven landscape of winners and losers. Various studies have highlighted time compression in inter-city rail travel from HSR network development but have overlooked the change in the location of rail stations, which prolongs intra-city travel time and counteracts the role of HSR services. Based on a high spatial resolution dataset of transport, land-use and population, this paper develops a door-to-door accessibility measurement by integrating the methods of cost distance analysis and network analysis. The paper examines changes in regional accessibility and the winners and losers of the shift from CR network to HSR network in the YRD. The use of different research methods on a multi-spatial scale reveals details on changing spatial patterns, the equity of accessibility, and the problems of accessibility improvement in regions because of ignoring the intra-city accessibility to railways stations and cities outside the HSR network.

Both CR and HSR networks generate core-periphery structure and corridor effects of territorial accessibility in the YRD, but the HSR network exhibits more powerful spatial influences on spatial structure and creates many high accessibility enclaves around HSR stations in the periphery areas. The findings show that the geographic location together with the rail network extension determines the patterns of regional territorial accessibility. HSR development has compressed regional travel time significantly, but the improvements vary across different sub-regions, cities, and stations. Some of the highest gains are in peripheral areas and main HSR corridors, while some HSR cities gain territorial accessibility improvements that are below average. Intra-city accessibility to HSR stations also plays an 
important role in regional accessibility improvements. The insignificant change in the spatial unevenness of territorial accessibility from the HSR network to the CR network further suggests the limited role of inter-station accessibility improvement in inter-city accessibility. However, the HSR network decreases the spatial unevenness of overall population accessibility significantly. Particularly, the development of intermediate stations along the Nanjing-Hangzhou HSR and Ningbo-Wenzhou HSR had made residents in cities like Liyang, Yixing and Taizhou-ZJ, access rail services for the first time. These cities are emerging 8 developed cities with relatively high population density and advanced industries. Therefore, the newly built HSRs particularly helped in improving population accessibility equity in the YRD in general.

In contrast to the experience in Europe where most HSR stations are upgraded CR stations for accommodating HSR trains (Banister and Givoni 2013), most HSR stations in the YRD are newly built and located at the edge of urban areas. The development strategy in China complicates the intra-city connectivity and accessibility to HSR stations. Consequently, the existence of an HSR station does not necessarily mean that a city will be a winner in regional accessibility improvements while the relative location of an HSR station from the city centre and its proximity to major population centres also plays an important role. The results suggest that poor access to the HSR station is a common issue for many cities in the YRD. However, what is worse is that along with rapid HSR development, many HSR cities in the YRD have proposed the construction of new towns around the station to promote the local property market and economic development. Obviously, the strategy may not be effective everywhere as previous studies have shown that HSR could polarise regional economies, and small cities would be further exploited by central cities (Jiao et al. 2014, Givoni 2006). In the context of China's continuous rapid urbanization, it might not be a problem for big cities with powerful centripetal forces to concentrate population and investment in their HSR new towns. However, small cities with low development opportunities and infrequent HSR train services may not be able to reap the benefits. Whether the HSR new towns located far away from the city centre in less populated small cities can attract residents and business remains questionable. Therefore, the role of HSR stations in the urban development of different cities in the YRD should be carefully examined.

Some limitations of this paper should be mentioned for future study. First, this paper did not take into account the availability of vehicle supply and waiting time at traffic lights and in traffic jams in the intra-city travel time calculation. Although our sample locations illustrate that the model results exaggerate approximately $10 \%$ of the accessibility to railway stations by car, the gap may be larger in the rural areas as the road conditions are relatively poor. The accessibility gap between public and private transport to HSR stations should also be evaluated in future spatial equity analyse. The issue is particularly important in the Chinese context where most people use public transport as their first choice. Second, there is a need to reconsider the least travel time principle for zoning railway catchment. Practically, the factors affecting travellers' station selection also include train frequency and the cost of train service. In future studies, time series accessibility could be acquired from online map queries. Third, currently, there are four HSR lines under planning and construction in the YRD; these are: Xuzhou-Xuqian-Huai'an-Yancheng HSR, Lianyungang-Yancheng HSR, Nantong-Shanghai 
HSR, and Shangqiu-Hefei-Hangzhou HSR. These lines will change the poor accessibility in northern Jiangsu province and the Hangzhou bay area in Zhejiang province.

Besides, the subway system is not included in the accessibility modelling in this paper. Nonetheless, it is not a significant problem for accessibility calculation because subways are typically parallel to major urban roads, and they operate at a similar speed when the road traffic conditions are ignored. Indeed, developing public transport and reducing traffic congestion are common agendas for many big cities in China. Several big cities like Shanghai, Nanjing, Hangzhou and Suzhou in the YRD have been building a subway system to connect rail stations and the city centre. The subway system becomes an important feeder of passengers for HSR services in the large cities. Consequently, a more sophisticated measure is needed to include the subway system for future HSR accessibility studies. Lastly, although the average fare per kilometer of travel for China's HSR was the cheapest compared with that for many other HSR cities (Freemark 2009), the average per capita income in China was much lower than that in many countries. This makes HSR services more or less an expansive transport mode in the Chinese context. Particularly, China is still a developing countries and the income disparity isg among the highest in the world (Xie and Zhou 2014). A recent survey along Beijing-Shanghai HSR shows that the majority of the passengers were from the middle to high-income groups (Chen et al. 2016a). HSR development may create a new dimension of transport inequity. Therefore, not only the accessibility, but also the affordability should be incorporated in future equity studies on HSR development in China.

\section{Acknowledgements}

This research is funded by Hallsworth Research Fellowship Fund (Chinese Political Economy) at the University of Manchester and National Science Foundation of China (41601169). The first author would like to thank Cecilia Wong for her insightful suggestions and comments, journal editor and anonymous reviewers for their detailed comments and suggestions that have led to a significant improvement of this paper.

No conflict is declared.

\section{References}

Banister, D. \& M. Givoni (2013) High-speed rail in the EU27: trends, time, accessibility and principles. Built Environment, 39, 324-338.

Bellet, C. (2016) Peripheral High-Speed Rail Stations in Spain. The Open Transportation Journal, 10, 45-56.

Button, K. (2012) Is there any economic justification for high-speed railways in the United States? Journal of Transport Geography, 22, 300-302.

Campa, J. L., M. E. López-Lambas \& B. Guirao (2016) High speed rail effects on tourism: Spanish empirical evidence derived from China's modelling experience. Journal of Transport Geography, 57, 44-54.

Campos, J. \& G. de Rus (2009) Some stylized facts about high-speed rail: A review of HSR experiences around the world. Transport Policy, 16, 19-28.

Cao, J., X. C. Liu, Y. Wang \& Q. Li (2013) Accessibility impacts of China's high-speed rail network. Journal of Transport Geography, 28, 12-21.

Cao, J. \& P. Zhu (2017) High-speed rail. Transportation Letters, 9, 185-186. 
Chandra, S. \& S. Vadali (2014) Evaluating accessibility impacts of the proposed America 2050 high-speed rail corridor for the Appalachian Region. Journal of Transport Geography, 37, 28-46.

Chen, C.-L. (2012) Reshaping Chinese space-economy through high-speed trains: opportunities and challenges. Journal of Transport Geography, 22, 312-316.

---. 2016. Transport and Place-Making: A Long View. In Sir Peter Hall: Pioneer in Regional Planning, Transport and Urban Geography, eds. R. D. Knowles \& C. Rozenblat, 37-58. Cham: Springer International Publishing.

Chen, C.-L. \& P. Hall (2013) Using High Speed Two to Irrigate the Regions. Built Environment, 39, 355-368.

Chen, C.-L. \& R. Vickerman (2017) Can transport infrastructure change regions' economic fortunes? Some evidence from Europe and China. Regional Studies, 51, 144-160.

Chen, H., D. Sun, Z. Zhu \& J. Zeng (2016a) The Impact of High-Speed Rail on Residents' Travel Behavior and Household Mobility: A Case Study of the Beijing-Shanghai Line, China. Sustainability, 8, 1187.

Chen, Z., J. Xue, A. Z. Rose \& K. E. Haynes (2016b) The impact of high-speed rail investment on economic and environmental change in China: A dynamic CGE analysis. Transportation Research Part A: Policy and Practice, 92, 232-245.

Diao, M., Y. Zhu \& J. Zhu (2016) Intra-city access to inter-city transport nodes: The implications of high-speed-rail station locations for the urban development of Chinese cities. Urban Studies, 0042098016646686.

Freemark, Y. 2009. Getting the Price Right: How Much Should High-Speed Fares Cost? The Transport Politic.

Garmendia, M., C. Ribalaygua \& J. M. Ureña (2012) High speed rail: implication for cities. Cities, 29, Supplement 2, S26-S31.

Gaughan, A. E., F. R. Stevens, Z. Huang, J. J. Nieves, A. Sorichetta, S. Lai, X. Ye, C. Linard, G. M. Hornby, S. I. Hay, H. Yu \& A. J. Tatem (2016) Spatiotemporal patterns of population in mainland China, 1990 to 2010. Scientific Data, 3, 160005.

Givoni, M. (2006) Development and impact of the modern high - speed train: a review. Transport Reviews, 26, 593-611.

Givoni, M. \& D. Banister (2012) Speed: the less important element of the High-Speed Train. Journal of Transport Geography, 22, 306-307.

Guirao, B. (2013) Spain: highs and lows of 20 years of HSR operation. Journal of Transport Geography, 31, 201-206.

Gutiérrez, J. (2001) Location, economic potential and daily accessibility: an analysis of the accessibility impact of the high-speed line Madrid-Barcelona-French border. Journal of Transport Geography, 9, 229-242.

Hall, P. \& D. Banister (1993) The second railway age. Built Environment, 19, 157.

Harrison, J. \& M. Hoyler. 2015. Megaregions: Globalization s New Urban Form? : Edward Elgar Publishing.

Jiao, J., J. Wang, F. Jin \& M. Dunford (2014) Impacts on accessibility of China's present and future HSR network. Journal of Transport Geography, 40, 123-132.

Johnson, B. E. (2012) American intercity passenger rail must be truly high-speed and transit-oriented. Journal of Transport Geography, 22, 295-296.

Kim, H. \& S. Sultana (2015) The impacts of high-speed rail extensions on accessibility and spatial equity changes in South Korea from 2004 to 2018. Journal of Transport Geography, 45, 48-61.

Levinson, D. M. (2012) Accessibility impacts of high-speed rail. Journal of Transport Geography, 22, $288-291$.

Li, G., X. Luan, J. Yang \& X. Lin (2013) Value capture beyond municipalities: Transit-oriented development and inter-city passenger rail investment in China's Pearl River Delta. Journal of Transport Geography, $33,268-277$. 
Li, Y. \& F. Wu (2017) Understanding city-regionalism in China: regional cooperation in the Yangtze River Delta. Regional Studies, 1-12.

Liu, X., B. Derudder \& M. Wang (2017) Polycentric urban development in China: A multi-scale analysis. Environment and Planning B: Urban Analytics and City Science, 2399808317690155.

Liu, X., B. Derudder \& K. Wu (2016) Measuring polycentric urban development in China: An intercity transportation network perspective. Regional Studies, 50, 1302-1315.

Martínez, H. S. \& M. Givoni (2012) The accessibility impact of a new High-Speed Rail line in the UK - a preliminary analysis of winners and losers. Journal of Transport Geography, 25, 105-114.

Mohino, I., A. Loukaitou-Sideris \& J. M. Urena (2014) Impacts of High-Speed Rail on Metropolitan Integration: An Examination of London, Madrid and Paris. International Planning Studies, 19, 306-334.

Monzón, A., E. Ortega \& E. López (2013) Efficiency and spatial equity impacts of high-speed rail extensions in urban areas. Cities, 30, 18-30.

Ollivier, G., R. Bullock, J. Ying \& N. Zhou (2014) High-Speed Railways in China.

Ortega, E., E. López \& A. Monzón (2012) Territorial cohesion impacts of high-speed rail at different planning levels. Journal of Transport Geography, 24, 130-141.

Perl, A. D. \& A. R. Goetz (2015) Corridors, hybrids and networks: three global development strategies for high speed rail. Journal of Transport Geography, 42, 134-144.

Rodrigue, J.-P., C. Comtois \& B. Slack. 2016. The Geography of Transport Systems. London: Taylor \& Francis.

Ryder, A. (2012) High speed rail. Journal of Transport Geography, 22, 303-305.

Salonen, M. \& T. Toivonen (2013) Modelling travel time in urban networks: comparable measures for private car and public transport. Journal of Transport Geography, 31, 143-153.

Scott, A. J. \& M. Storper (2007) Regions, globalization, development. Regional Studies, 41, S191-S205.

Shaw, S.-L., Z. Fang, S. Lu \& R. Tao (2014) Impacts of high speed rail on railroad network accessibility in China. Journal of Transport Geography, 40, 112-122.

Ureña, J. M., P. Menerault \& M. Garmendia (2009) The high-speed rail challenge for big intermediate cities: A national, regional and local perspective. Cities, 26, 266-279.

Vickerman, R. (1997) High-speed rail in Europe: experience and issues for future development. The Annals of Regional Science, 31, 21-38.

--- (2017) Can high-speed rail have a transformative effect on the economy? Transport Policy.

Wang, J., F. Jin, H. Mo \& F. Wang (2009) Spatiotemporal evolution of China's railway network in the 20th century: An accessibility approach. Transportation Research Part A: Policy and Practice, 43, 765-778.

Wang, J. J., C. Rong, J. Xu \& S. W. O. Or (2012) The funding of hierarchical railway development in China. Research in Transportation Economics, 35, 26-33.

Wang, J. J., J. Xu \& J. He (2013) Spatial impacts of high-speed railways in China: a total-travel-time approach. Environment and Planning A, 45, 2261-2280.

Wang, L., Y. Liu, C. Sun \& Y. Liu (2016) Accessibility impact of the present and future high-speed rail network: A case study of Jiangsu Province, China. Journal of Transport Geography, 54, 161-172.

Wu, J., C. Nash \& D. Wang (2014) Is high speed rail an appropriate solution to China's rail capacity problems? Journal of Transport Geography, 40, 100-111.

Xie, Y. \& X. Zhou (2014) Income inequality in today's China. Proceedings of the National Academy of Sciences, 111, 6928-6933.

Zhao, P. \& S. Li (2017) Bicycle-metro integration in a growing city: The determinants of cycling as a transfer mode in metro station areas in Beijing. Transportation Research Part A: Policy and Practice, 99, 46-60. 
1 Zhu, P., T. Yu \& Z. Chen (2015) High-Speed Rail and Urban Decentralization in China. Transportation Research Record: Journal of the Transportation Research Board, 16-26. 